\title{
FRICTIONAL AND NON-FRICTIONAL UNEMPLOYMENT IN A LABOR MARKET WITH MATCHING FRICTIONS*
}

\author{
by \\ Universitat de València \\ and \\ VALERI SOROLLA $A^{\dagger}$ \\ Universitat Autònoma de Barcelona and BGSE
}

\begin{abstract}
Using the Mortensen and Pissarides model of a labor market with frictions, this paper proposes a new method, simpler than the one presented in Michaillat (2012), for decomposing unemployment into frictional and non-frictional (rationing) unemployment for a derived rigid wage-setting rule. We use it to compute the frictional and non frictional unemployment rate for two economies characterized by different labor market institutions, namely the US and the Spanish economy. For the entire period under study, the US frictional unemployment rate is around 36 per cent of total unemployment, whereas for Spain, approximately 20 per cent of all unemployment is due to frictions. This outcome may be explained by the fact that Spain is a country with more labor market rigidities than the US. The empirical results obtained with our method are also consistent with the main result of Michaillat (2012): in both countries, non-frictional unemployment increases in recessions.
\end{abstract}

\section{INTRODUCTION}

The Great Recession was the most severe recession experienced to date by the US and the euro area economies in terms of Gross Domestic Product (GDP) and the rise in unemployment. This dramatic increase in unemployment in recent years has reopened the debate over the causes of unemployment. For example, Kocherlakota (2010) claims that rising unemployment is associated with an increase in structural unemployment, while Krugman (2010) explains that the problem lies in a weak aggregate labor demand, which makes it Keynesian unemployment. In another theoretical framework, Michaillat (2012) divides unemployment into frictional and rationing, and measures the different weight of both components over the business cycle using US data.

\footnotetext{
* Manuscript received 3.12.14; final version received 19.2.16.

† We are indebted to José I. Silva and Héctor Sala for their helpful suggestions and comments on a preliminary version of this paper as well as participants at the XXXVII (SAEe) and the X JEL. García is grateful to the Spanish Ministry of Education for financial support through grant ECO2010-21539 and Eco2014-53150-R. Sorolla is grateful to the Spanish Ministry of Economy and Competitiveness for financial support through grant ECO2015-67602-P and to the Generalitat of Catalonia through grant 2014 SGR 803.
} 
Why is it important to decompose the unemployment rate into its main components? Breaking down the observed rate of unemployment is vital for policy makers since it allows them to choose the appropriate policy to apply. For example, the findings of theoretical and empirical research suggest that reducing labor mobility costs, providing training programs for developing worker skills or reducing unemployment benefits all reduce frictional unemployment, whereas fiscal policy does not affect it.

It therefore, necessary to establish the sources of aggregate unemployment by means of empirical and theoretical analysis, to implement policies that will reduce the aggregate unemployment rate in the future. This article contributes to the literature by introducing a new method to disentangle the unemployment rate into rationing/non-frictional and frictional unemployment.

If one wants to determine frictional and rationing unemployment rates, one has to introduce frictions in the labor market by a matching function and a wage-setting rule. However, that also raises the question of how much employment is due to the wage being set above the competitive wage and how much is due to matching frictions. To answer this question, the labor market must be analyzed using the same wage-setting rule and eliminating frictions.

Michaillat (2012) does just that, and shows that with a wage equation based on the standard surplus sharing rule, if one eliminates frictions and if the wage is set at the competitive wage rate, then there is no unemployment without frictions and all the employment obtained when there are frictions is frictional. ${ }^{1}$ To have non-frictional (rationing) unemployment, the wage-setting rule must be changed. Michaillant shows that if the wage rule implies rigid wages, in the presence of diminishing marginal product of labor, there is unemployment when frictions are eliminated. This means that only part of the unemployment generated when there are frictions is in fact frictional unemployment. Finally, he analyzes how frictional and non-frictional unemployment change with this same wage-setting rule when there are technological shocks.

This paper follows Michaillat's procedure, developing some aspects not addressed in his model. First, he assumes that eliminating frictions means making the cost of opening a vacancy equal to zero. However, this implies that the matching frictions in the labor market do not disappear. We take an alternative approach to that of Michaillat (2012), using a matching function that eliminates frictions and maintaining a positive cost for opening a vacancy. ${ }^{2}$ As in Michaillat (2012), we show that non-frictional unemployment can also occur with rigid wages and diminishing marginal product of labor, but the problem of using this wage rule is that it must be deduced. We

\footnotetext{
${ }^{1}$ Even with constant or decreasing marginal product of labor.

${ }^{2}$ For example, Mortensen and Pissarides (2001) show the role played by the cost of recruiting on the one hand and hiring and training costs on the other. More recently, Brown et al. (2015) explain that vacancy posting costs are incurred before firms and workers make contact, whereas the hiring cost is incurred by the firm after contact is made. In this paper, we focus on the cost of recruiting or vacancy posting cost.
} 
derive it using the standard union monopoly model in a labor market with frictions.

The second contribution of this paper is to derive an empirical method for measuring frictional and rationing unemployment, different to the one used by Michaillat and also simpler. With this method we decompose the observed unemployment rate into frictional and non-frictional unemployment for the US labor market. We do the same for the Spanish economy because it represents the other extreme of the labor market, characterized as it is by collective bargaining and higher labor market regulations.

The advantage of following our proposed method, to decompose the aggregate unemployment rate, is its simplicity. Nevertheless, or results are in line with Michaillat's principal result for both economies. The frictional unemployment rate is countercyclical and the unemployment rate due to rationing is procyclical.

With our method, we observe for the US labor market that the average unemployment rate for the recession years is 7 per cent. Over this period, the frictional unemployment is about 1.9 per cent and the rationing unemployment rate is 5.1 per cent. Moreover, as long as unemployment is below 5 per cent almost all unemployment is frictional. These numbers are roughly consistent with Michaillat' s (2012) results. For the entire period, frictional unemployment is around 36 per cent of total unemployment. Conversely, the empirical decomposition over the whole period for Spain suggests that approximately 20 per cent of all unemployment is frictional and the other 80 per cent is rationing unemployment. These results are consistent with a large body of literature that shows the higher degree of institutional rigidity and high levels of wage rigidity for the Spanish labor market. Our results mean that policies that reduce frictional unemployment will contribute more to the reduction of unemployment in the US than in Spain, where policies of wage moderation will be more effective for reducing unemployment.

The remainder of the paper is organized as follows. In the next section, we present a model to determine the amount of frictional and non frictional employment in a labor market with frictions under a rigid wage equation that we derive. The third section is devoted to computing the frictionalrationing unemployment rate for the US and Spain. The fourth section presents some comments and concluding remarks.

\section{Theoretical Framework}

\subsection{Employment in a Labor Market With and Without Frictions Under a Rigid Wage Equation}

In this section, we describe the key features of the labor market matching framework with frictions and compare it to the equivalent framework without frictions. Using a discrete-time model in a labor market with frictions, 
there is a matching function with constant return to scale $h\left(u_{t}, v_{t}\right)<\min \left(u_{t}\right.$, $v_{t}$ ) where $u_{t}$ is the number of unemployed workers, $v_{t}$ is the number of vacancies and, as usual, labor market tightness is given by $\theta_{t} \equiv \frac{v_{t}}{u^{\prime}}$. We define the probability of the firm to filling an open vacancy as $q(\theta) \stackrel{u_{t}}{\equiv} \frac{h(u, v)}{v}$, and thus $\frac{1}{q(\theta)}$ is the mean duration of a vacant job. ${ }^{3}$ The probability of an unemployed worker finding a job is defined as $f(\theta) \equiv \frac{h(u, v)}{u}$ and, thus $\frac{1}{f(\theta)}$ is the mean duration of unemployment. For a large competitive firm, with neoclassical production function $g(n, a)=a n^{\alpha}(\alpha<1)$, the amount of employment $n$ chosen by the firm in a labor market with frictions in a stationary equilibrium is given by the employment equation ${ }^{4}$ :

$$
\frac{\partial g}{\partial n}=\alpha a(n)^{\alpha-1}=w+(1-(1-s) \delta) \frac{c}{q(\theta)}
$$

where $w$ is the real wage, $c$ the cost of opening a vacancy, $\delta$ the discount (real interest rate) and $s$ the exogenous separation rate. ${ }^{5}$ We interpret these conditions as meaning that the marginal product of labor is equal to its cost, i.e. the sum of wage $w$ and the average cost of a vacant job $\frac{c}{q(\theta)}$.

If we assume that the cost of opening a vacancy is proportional to the wage $c=\bar{c} w$, then the employment equation may be written as follows:

$$
\alpha a(n)^{\alpha-1}=\left[1+(1-(1-s) \delta) \frac{\bar{c}}{q(\theta)}\right] w
$$

The explicit solution for $n$ gives:

$$
n=\left[\frac{\left[1+(1-(1-s) \delta) \frac{\bar{c}}{q(\theta)}\right] w}{\alpha a}\right]^{-\frac{1}{1-\alpha}}
$$

with the elasticity of employment with respect to the wage being constant and equal to $\frac{1}{1-\alpha}$.

To close the model with frictions we assume equilibrium in the labor market flows which gives the Beveridge curve ${ }^{6}$

$$
\frac{n}{l}=\frac{1}{(1-s)+\frac{s}{f(\theta)}}
$$

where $l$ is an inelastic labor supply and $\frac{n}{l}$ the employment rate. Hence, for a given wage, the equations (1) and (4) determine $n$ and $\theta$ in a labor market with frictions.

\footnotetext{
${ }^{3} \mathrm{We}$ omit the time index when it is not necessary.

${ }^{4} \mathrm{We}$ assume that $\theta$ is constant. See Michaillat (2012) equation (14).

${ }^{5}$ For the continuous case the condition is $\frac{\partial g}{\partial n}=\alpha a(n)^{\alpha-1}=w+(s+\delta) \frac{c}{q(\theta)}$, see e.g. Cahuc et al. (2014) equation (9.46) or Pissarides (2000) equation (1.30).

${ }^{6}$ See Michaillat (2012) equation (3) where he assumes that $l=1$.

(c) 2016 The University of Manchester and John Wiley \& Sons Ltd
} 
In a labor market without frictions, we assume that $h(u, v)=\min (u, v)$, instead of assuming $\bar{c}=0$ as Michaillat (2012) does. Now if $v \leqq u$ then $\theta \leqq 1$ and $h(u, v)=\min (u, v)=v$ in which case $q(\theta) \equiv \frac{h(u, v)}{v}=1$ and, using (2), the amount of employment chosen by the firm in a labor market without frictions in a steady state $n_{\mathrm{nf}}$ is given by the equation:

$$
\alpha a\left(n_{\mathrm{nf}}\right)^{\alpha-1}=[1+(1-(1-s) \delta) \bar{c}] w
$$

which gives the amount of non frictional employment:

$$
n_{\mathrm{nf}}=\left[\frac{[1+(1-(1-s) \delta) \bar{c}] w}{\alpha a}\right]^{-\frac{1}{1-\alpha}}
$$

so there is non-frictional or rationing unemployment $u_{\mathrm{nf}}$ when the wage is such that $l-n_{\mathrm{nf}}>0$ and thus the non-frictional unemployment rate is

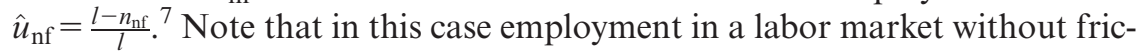
tions is given using only the employment equation and then we use the Beveridge curve to get $\theta_{\text {nf. }}^{8}$

Finally, if $v>u$, then $\theta>1$ and $h(u, v)=\min (u, v)=u$ in which case $f(\theta) \equiv \frac{u}{u}=1$ and using the Beveridge curve we obtain $n_{\mathrm{nf}}=l$, it means that there is full employment.

Next, we decompose the aggregate unemployment into two easily interpretable components: non-frictional or rationing unemployment $u_{\mathrm{nf}}$ and frictional unemployment $u_{\mathrm{f}}$. We can define the aggregate unemployment as

$$
u=l-n=l-n_{\mathrm{nf}}+n_{\mathrm{nf}}-n
$$

where, as we said, $l-n_{\mathrm{nf}}$ is defined as rationing unemployment and $n_{\mathrm{nf}}-n$ is defined as frictional unemployment, so $u=u_{\mathrm{nf}}+u_{\mathrm{f}}$. Then frictional unemployment rate is $\hat{u}_{\mathrm{f}}=\frac{u_{\mathrm{f}}}{l}$.

Thus, using (6) and (3) we have

$$
\begin{aligned}
u_{\mathrm{f}}= & n_{\mathrm{nf}}-n=\left[\frac{[1+(1-(1-s) \delta) \bar{c}] w}{\alpha a}\right]^{-\frac{1}{1-\alpha}} \\
& -\left[\frac{\left[1+(1-(1-s) \delta) \frac{\bar{c}}{q(\theta)}\right] w}{\alpha a}\right]^{-\frac{1}{1-\alpha}}
\end{aligned}
$$

Following Michaillat (2012) one can show that

\footnotetext{
${ }^{7}$ If one assumes that in a labor market without frictions $\bar{c}=0$, as Michaillat does, $n_{\mathrm{nf}}$ is given by $\alpha a\left(n_{\mathrm{nf}}\right)^{\alpha-1}=w$.

${ }^{8}$ Of course it must be true that $\theta_{\mathrm{nf}}<1$.

(C) 2016 The University of Manchester and John Wiley \& Sons Ltd
} 


$$
\frac{\partial u_{\mathrm{f}}}{\partial a}=\frac{\partial n_{\mathrm{nf}}}{\partial a}-\frac{\partial n}{\partial a}=\frac{\left[\frac{[1+(1-(1-s) \delta) \bar{c}] w}{\alpha a}\right]^{-\frac{1}{1-\alpha}}}{\partial a}-\frac{\left[\frac{\left[1+(1-(1-s) \delta) \frac{\bar{c}}{q(\theta)}\right] w}{\alpha a}\right]^{-\frac{1}{1-\alpha}}}{\partial a}>0
$$

this implies that, in bad times (when $a$ decreases), frictional unemployment decreases.

We can rewrite the amount of frictional unemployment as

$$
u_{\mathrm{f}}=n_{\mathrm{nf}}-n=\frac{n_{\mathrm{nf}}-n}{n} . n=\left(\frac{n_{\mathrm{nf}}}{n}-1\right) n
$$

Plugging (6) and (3) into (10), and rearranging gives ${ }^{9}$

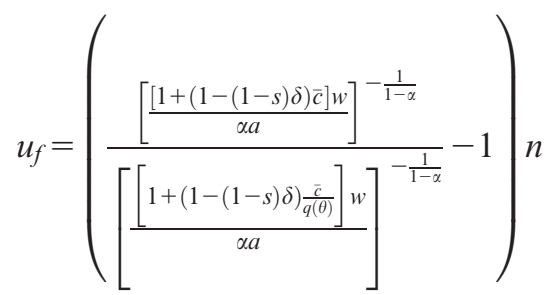

$$
\begin{aligned}
& =\left(\left[\frac{\left[1+(1-(1-s) \delta) \frac{\bar{c}}{q(\theta)}\right]}{[1+(1-(1-s) \delta) \bar{c}]}\right]^{\frac{1}{1-\alpha}}-1\right) n
\end{aligned}
$$

To empirically decompose the unemployment rate, we need a specific functional form for the matching function. We assume the standard CobbDouglas matching function with constant returns to scale:

$$
h\left(u_{t}, v_{t}\right)=\mu u_{t}^{\eta} v_{t}^{1-\eta}
$$

where $\mu$ stands for a scale parameter that captures the aggregate matching efficiency and $\eta$ is the elasticity of new hires with respect to unemployment. The probability of a vacancy being filled is equal to $q(\theta)=\frac{h(u, v)}{v}=\frac{\mu}{\theta^{\prime \prime}}$ and then the amount of frictional unemployment is

$$
u_{\mathrm{f}}=\left(\left[\left[\frac{\left[1+(1-(1-s) \delta) \bar{c} \frac{\theta^{\eta}}{\mu}\right]}{[1+(1-(1-s) \delta) \bar{c}]}\right]^{\frac{1}{1-\alpha}}-1\right) n\right.
$$

${ }^{9}$ If, as in Michaillat (2012), we assume that no frictions means $\bar{c}=0$, then
$u_{\mathrm{f}}=\left(\left[1+(1-(1-s) \delta) \frac{\bar{c}}{q(\theta)}\right]^{\frac{1}{1-\alpha}}-1\right) n$. 
and, thus the frictional unemployment rate is given by

$$
\hat{u}_{\mathrm{f}}=\left(\left[\frac{\left[1+(1-(1-s) \delta) \bar{c} \frac{\theta^{\eta}}{\mu}\right]}{[1+(1-(1-s) \delta) \bar{c}]}\right]^{\frac{1}{1-\alpha}}-1\right) \frac{n}{l}
$$

which means that, to compute the frictional unemployment rate, we need data for the exogenous separation rate $s$, the interest rate to compute the discount factor $\delta$, the proportion of the wage for opening a vacancy $\bar{c}$, the parameters of the matching function $\mu$ and $\eta$, the labor share $\alpha$ and, assuming that $\theta$ and $n$ coincide with the observed data, the observed labor market tightness and the employment rate $n$ (employment/labor force).

\subsection{Comparison with Michaillat's Method for Computing the Frictional Unemployment Rate}

Assuming that observed employment coincides with $n$ the amount of non frictional unemployment in the steady state is given by equation 8, i.e $^{10}$ :

$$
u_{\mathrm{f}}=n_{\mathrm{nf}}-n=\left[\frac{[1+(1-(1-s) \delta) \bar{c}] w}{\alpha a}\right]^{-\frac{1}{1-\alpha}}-n
$$

which one can compute using data for the exogenous separation rate $s$, the discount factor $\delta$, the proportion of the wage required to open a vacancy $\bar{c}$, the labor share $\alpha$, the wage $w$ and the technology shock $a{ }^{11}$ The difference between this method (Michaillat-M) and the one described in the previous section (García and Sorolla-GS) is that the M method uses data on wages and technology shocks and the GS method uses basically the parameters of the matching function $\mu$ and $\eta$ and the labor market tightness. ${ }^{12}$

\subsection{How Can We Obtain a Rigid Wage Equation?}

To perform the decomposition, it is crucial to have a rigid wage equation that does not depend on employment ensuring that the wage set is the same,

\footnotetext{
${ }^{10}$ Alternatively Michaillat computes $n$ outside the steady state using the dynamic (non-linear) model, composed of the wage equation, the employment equation [equation (7)] and the labor market flows equation, using the Fair and Taylor (1983) shooting algorithm.

${ }^{11}$ This is because Michaillat (2012) $\bar{c}=0$ computes it using $u_{\mathrm{f}}=\left[\frac{w}{\alpha a}\right]^{-\frac{1}{1-\alpha}}-n$. In Section A3 of the online appendix, he computes the $a$ (A3.1), $a$ and $w$ (A3.2), $a, w$, and $\mu$ (A3.3), generated by the employment equation with frictions, the labor market flows equation and the production function in the steady state using data for $u, \theta$, and production $y$.

${ }^{12}$ Moreover, the empirical strategy of this paper differs from Michaillat because our results are based on the estimation of matching parameters using observed data. Michaillat, on the other hand, uses the calibration of the parameter and, then simulates frictional and rationing unemployment $\theta$.
} 
independently of whether there are frictions or not. Michaillat (2012) formalizes real wage rigidity by employing the following ad hoc wage equation

$$
w_{t}=\bar{w}\left(A_{t}\right)^{\psi},
$$

where $0<\psi<1$ (estimation $\psi=0.7$ ), which appears in Blanchard and Galí (2010). This wage equation assumes that wages do not depend on employment and that they partially adjust to technology shocks. In the standard matching model, it is difficult to derive this wage equation for a number of reasons. The literature typically assumes individual wage bargaining and as such that wages and employment are set at the same time, which gives the generalized bargained wage equation. ${ }^{13}$ Alternatively, during negotiations the employment is agreed upon first, followed by the wages, which gives the Stole and Zwiebel wage equation where again wages depend on employment. ${ }^{14}$ Nevertheless, when one assumes collective bargaining there is a straightforward way to obtain wage rigidity: to assume that wages are set before employment. One way to model this is to consider that there is a union in the labor market that acts as a Stackelberg leader, knowing the employment equation when there are frictions and when there are no frictions. In both cases the union maximizes $\left(\omega-b_{0}\right) L$, where $b_{0}$ is the unemployment benefit. This means a collective wage-setting rule, where the union sets the same wage for all employed workers maximizing the surplus on an employed worker times the number of employed workers. It is well known that in this case the wage is a mark up $m=\frac{1}{1-\frac{1}{2}}$, over the unemployment benefit that depends on the elasticity $\varepsilon$ of the employment function. ${ }^{15}$ For example, if the production function is Cobb-Douglas $\left(g(n, a)=a n^{\alpha}\right)$, the elasticity of both $L_{\mathrm{F}}$ and $L_{\mathrm{NF}}$ is the same and equal to $\frac{1}{1-\alpha}$, in which case $w_{\mathrm{F}}=$ $w_{\mathrm{NF}}=\bar{w}=\frac{b_{0}}{\alpha}$. Moreover, if one assumes that $b_{0}=b A^{\psi}$, that is unemployment benefits are sensitive to the cycle, then one gets the wage equation proposed by Blanchard and Galí (2010).

\section{Empirical Decomposition}

In this section, we present the decomposition exercise that enables us to determine how much of the aggregate unemployment rate is attributable to either frictional or rationing unemployment. Frictional unemployment is characterized by the existence of search and matching frictions between

\footnotetext{
${ }^{13}$ In these negotiations the wage depends on employment. Specifically, outside the steady state this wage equation is given in Lemma 1 in Michaillat (2012) but assuming $g(n, a)=a n$.

${ }^{14}$ Outside the steady state this wage equation is given in Lemma 2 in Michaillat (2012) for $g(n, a)=a n^{\alpha}$.

${ }^{15}$ One may get the same type of wage equation, for individual wage setting. When the firm sets the wage in an efficient wage environment, the mark up over unemployment benefits depends on the parameter of the effort function.

(C) 2016 The University of Manchester and John Wiley \& Sons Ltd
} 
TABLE 1

Parameter Values, Quarterly Data

\begin{tabular}{llll}
\hline Parameter & Value & \multicolumn{1}{c}{ Description } & \multicolumn{1}{c}{ Source/Target } \\
\hline$\alpha$ & 0.67 & Share of labor & OECD (MEI) \\
$\eta$ & 0.94 & Beveridge elasticity & Estimated Value \\
$c$ & 0.12 & Vacancy cost & Silva and Toledo (2009) \\
$\mu$ & 1.08 & Matching function scale & Estimated Value \\
$s$ & 0.07 & Separation rate & Shimer (2005) \\
Data, Mean Values & & & \\
$u$ & $6,45 \%$ & Unemployment & OECD (MEI) \\
$\frac{1}{q(\theta)}$ & 0.57 & Duration of a vacancy & OECD(MEI) \\
$c / q(\theta)$ & 0.07 & Flow cost of recruiting & Calculated Value \\
$\delta$ & 0.986 & Discount factor & Calculated Value \\
\hline
\end{tabular}

workers and firms in the labor market due to coordination failures and mismatch between the characteristics of the unemployed workers and requirements for vacant jobs, e.g. in terms of skills or geographical location. ${ }^{16}$ The second category consists of unemployment due to wage setting above market-clearing level, in which wages are set by an economic agent (e.g. firms, workers, or the government). The concept of job rationing due to wage setting has long been a popular topic in the economic literature. ${ }^{17}$

We first compute the frictional unemployment rate, $\hat{u}_{\mathrm{f}}$ using, from the previous section, expression (13). We then, compute rationing unemployment as the difference between the observed unemployment rate, $\hat{u}$, and frictional rate, i.e.: $\hat{u}_{\mathrm{nf}}=\hat{u}-\hat{u}_{\mathrm{f}}$. We apply our method for decomposing the unemployment rate to the US and Spanish labor markets. It should be noted that this method is very general and may, therefore, be used for any country.

\subsection{USA}

We begin the analysis by focusing on the US economy using our method and comparing the results with those reported in Michaillat (2012). We believe this to be a good test to demonstrate the validity of our method for decomposing the unemployment rate. We subsequently perform a similar exercise for the aggregate unemployment rate in Spain.

Table 1 lists the values of the parameters used to decompose the unemployment rate for the US economy.

The analysis covers the period dating from 1980Q1 to 2013Q2. The data are published by the OECD Main Economic Indicators (MEI) database. More specifically, GDP and labor income data come directly from the

\footnotetext{
${ }^{16}$ For a survey on aggregate matching function studies and microfoundations, see e.g. Petrongolo and Pissarides (2001) and Stevens (2007).

${ }^{17}$ Recent research has turned its attention to rigid wages to explain the higher unemployment rate. See, e.g. Blanchard and Galí (2010) and Michaillat (2012). 
United States Department of Commerce, Bureau of Economic Analysis, while the labor force statistics are provided by the United States Population \& Labor Force US Bureau of Labor Statistics (BLS). Our data on unfilled job vacancies are based on: (i) the number of help-wanted advertisements published in the classified sections of newspapers and collected by the Conference Board (1980-2000); and (ii) the Job Openings and Labor Turnover Survey provided by the BLS of the US Department of Labor (20002013Q2). ${ }^{18}$

To compute the frictional/mismatch unemployment rate $\hat{u}_{\mathrm{f}}$, we must calculate or estimate some parameters. The parameter $\alpha$ is calculated as the ratio of total compensation of employees over GDP. According to our calculations, the average labor share is equal to 0.67. Taking the US data on unemployment and employment, we use Shimeŕ s methodology to calculate a job separation rate $s_{t}$, that varies for each quarter. We determine an average of 0.07 per quarter, which is widely used in the literature and consistent with empirical estimates. ${ }^{19}$

We obtain the total number of new hires (matches) $h_{t}$ from the expression $h_{t}=n_{t}-n_{t-1}(1-s)$, where $n$ is the employment level and $s$ the separation rate. Next, we use Ordinary Least Squares (OLS) to estimate, the aggregate matching function in the log linear form with non-detrended quarterly data to obtain an elasticity estimated coefficient $\eta$ equal to 0.94 . This value is in line with other empirical contributions to this literature (see Section 2 of Petrongolo and Pissarides (2001) for a survey over these issues). After estimating the parameter $\eta$ we inferred the aggregate matching efficiency, for each quarter, using the matching curve relationship implied by equation (11). This method of computing the aggregate matching efficiency reveals a cyclical pattern in line with empirical evidence (Barnichon and Figura (2011, 2013), Herz and Van Rens (2011)). ${ }^{20}$

Finally, we set a constant vacancy $\operatorname{cost} c=0.12$, which represents a reasonable quarterly value within the range used by other studies. ${ }^{21}$ Taking into account this vacancy cost and the rate at which firms contact workers, $q\left(\theta_{t}\right)$, we compute the expected recruitment cost per worker, $c / q\left(\theta_{t}\right)$, with a plausible average quarterly value of 0.075 . This recruitment cost per worker is in line with the estimated values obtained in the literature. For instance, Michaillat (2012) sets a flow cost of recruiting equal to 0.32 per month, which is approximately equivalent to 0.10 per quarter. Similarly, Shimer

\footnotetext{
${ }^{18}$ We combine both series to obtain data for a longer sample period. For an interesting discussion on these issues see, for instance, Yashiv (2006).

${ }^{19}$ See, e.g. Shimer (2005), Silva and Toledo (2009) and Michaillat (2012).

${ }^{20}$ In the literature, the estimated efficiency parameter shows a great dispersion due to different specifications and variables used to estimate the above mentioned matching function.

${ }^{21}$ See, e.g. Shimer (2005), Hagedorn and Manovskii (2008), Pissarides (2009) and Michaillat (2012).

(C) 2016 The University of Manchester and John Wiley \& Sons Ltd
} 


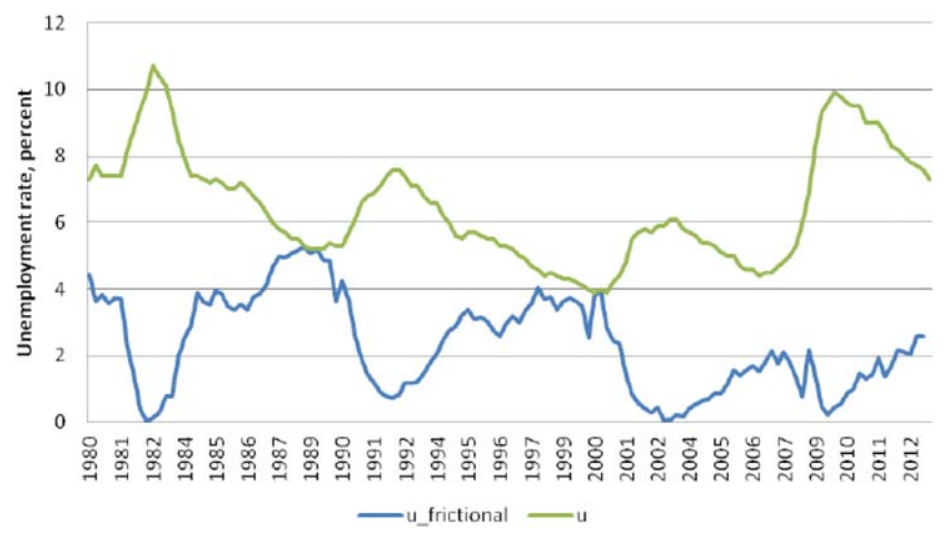

FIG. 1. Decomposition unemployment rate for US [Colour figure can be viewed at wileyonlinelibrary.com]

(2005) and Pissarides (2009) choose a cost of approximately 0.15 of a worker's quarterly wage.

Figure 1 shows the evolution of the overall unemployment rate and the frictional unemployment rate in the US.

It is worth stressing three aspects of the results. First and foremost, we find that in recessions rationing unemployment increases, driving the rise in total unemployment while frictional unemployment falls. Thus, our empirical results are consistent with Michaillat's (2012) work, despite using a different technique.

Second, the average frictional/mismatch unemployment rate is around 2.3 per cent, while rationing unemployment stands at around 4.1 per cent over this period, with frictional unemployment thus making up 36 per cent of total unemployment. More specifically, we observe an average unemployment rate for the recession years of 7 per cent. Over this period, the frictional unemployment is about 1.9 per cent and the rationing unemployment rate is 5.1 per cent. It should also be noted that in our empirical decomposition, based on expression (13), as long as unemployment is below 5 per cent almost all unemployment is frictional. This result is also similar to the findings of Michaillat (2012) with respect to the US.

Third, rationing unemployment has an important cyclical component. $^{22}$

To sum up, we have decomposed of the unemployment rate into frictional and rationing unemployment by means of a more simple technique than that proposed by Michaillat (2012); nevertheless the results obtained

\footnotetext{
${ }^{22}$ These results are in line with the work by Abraham and Katz (1986) and Herz and Rens (2011), among others.

C 2016 The University of Manchester and John Wiley \& Sons Ltd
} 
TABLE 2

Parameter Values, Quarterly Data

\begin{tabular}{lcll}
\hline Parameter & Value & Description & \\
$\alpha$ & 0.66 & Share of labor & Source/Target \\
$\eta$ & 0.87 & Beveridge elasticity & Data BDREMS/INE \\
$c$ & 0.12 & Vacancy cost & Estimated Value \\
$\mu$ & 0.7 & Matching function scale & Michaillat (2012) \\
$s$ & 0.1 & Separation rate & Shimer (2005) \\
Data, Mean Values & & Unemployment & Data BDREMS/INE \\
$u$ & $17 \%$ & Duration of a vacancy & Data BDREMS/INE \\
$\frac{1}{q(\theta)}$ & 0.59 & Flow cost of recruiting & Data BDREMS/INE \\
$c / q(\theta)$ & 0.08 & Discount factor & Calculated Value \\
$\delta$ & 0.98 & & \\
\hline
\end{tabular}

using our method are consistent with those of his work..$^{23}$ Our aim is to offer a complementary method to the one developed by Michaillat to address an important issue in the business cycle: the decomposition of the unemployment rate.

Lastly, we check the robustness of the results to: (i) a change in the vacancy cost $c$; (ii) a change in the elasticity of employment with respect to labor demand $\eta$; and (iii) a change in the matching function scale $\mu$. Recalculating the decomposition of the unemployment rate we find that, in general, a higher vacancy cost or a lower elasticity or matching function scale leads to a rise in frictional/mismatch unemployment.

\subsection{Spain}

We analyze the situation in Spain since it represents a very different labor market. We wanted to verify that, with different labor market institutions, the method of decomposing the unemployment yields the same qualitative outcomes as those of Michaillat (2012): namely, that frictional unemployment is clearly anticyclical, rationing unemployment is procyclical and at times of high economic expansion all unemployment is frictional. We also want to know the mean decomposition of unemployment for the entire period.

Table 2 presents the parameter values used to decompose the unemployment rate for Spain. The methodology used to obtain the parameters $(\alpha, \eta, \mu, s)$ is the same as that used for the US.

We employ quarterly data covering the period 1980 to 2013Q2. The data on the variables that we use (the unemployment rate, the vacancy rate, etc.) were obtained from two sources. The number of vacancies per quarter is provided by the REMSDB macroeconomic database compiled to simulate

\footnotetext{
${ }^{23} \mathrm{It}$ is important to point out that we also assume an alternative approach using a matching function that eliminates frictions and maintains a positive cost for opening a vacancy. 


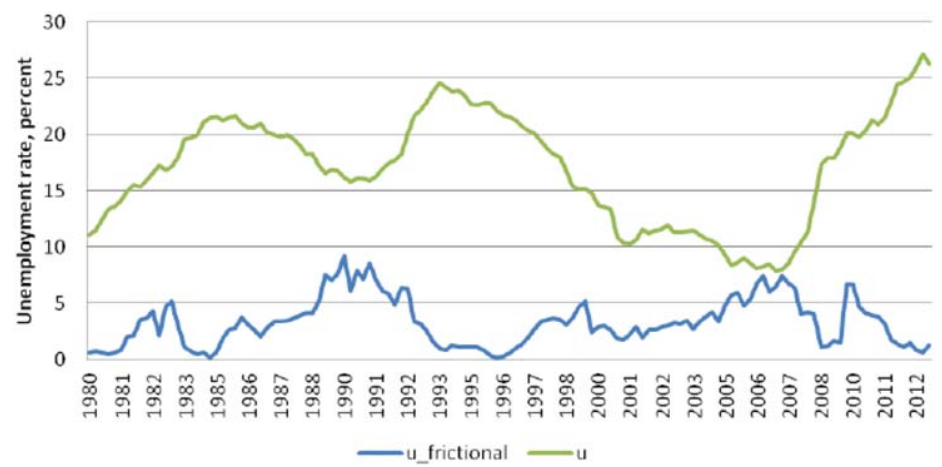

FIG. 2. Decomposition unemployment rate for Spain [Colour figure can be viewed at wileyonlinelibrary.com]

and calibrate the Rational Expectations Model (REMS) for the Spanish economy. The rest of the data comes from the Spanish Quarterly National Accounts (SQNA) and the Encuesta de Población Activa (Labor Force Survey) provided by the Instituto Nacional de Estadística (INE; National Statistical Institute).

It is important to point out that the estimated coefficient $\varphi=0.87$ is consistent with the range of values estimated in other more extensive studies of the Spanish labor market. ${ }^{24}$

We set the value of the vacancy posting cost to $\gamma=3$ per cent of annual labor costs per worker. ${ }^{25}$ This value is in line with the calibration by Sala and Silva (2009), who find that the hiring cost of new hired workers represents 2 per cent of the annual wage. However, other studies focusing on the Spanish labor market estimate a unit hiring cost of between 10 per cent and 16 per cent of the gross annual wage of a permanent worker (see, for instance, Alonso-Borrego et al. (2006)). More recently, Aguirregabiria and Alonso Borrego (2009) estimated hiring costs for temporary and permanent workers using a panel of 2356 Spanish manufacturing firms. They found that hiring costs are similar and that values range from 10 per cent to 18 per cent of workers annual salaries. We take the most conservative of these scenarios and set this cost at 3 per cent, since we assume that it reflects the time and money involved in the screening process for opening a vacancy.

Figure 2 displays the observed unemployment rate in the Spanish labor market over the period under study, and the decomposition between frictional and rationing unemployment; the pattern highlights several points of interest.

\footnotetext{
${ }^{24}$ See e.g. Burda and Wyplosz (1994), Peracchi and Viviano (2004) and Álvarez de Toledo (2007).

${ }^{25}$ If we increase the value of this parameter, we obtain a higher frictional unemployment rate. 
First, the unemployment rate in Spain is characterized by a larger sample mean than the US economy. In fact, a permanent feature of the Spanish economy is both the high level and the persistence of unemployment along the sample considered. More specifically, the average unemployment rate from 1980 to 2013 is 17 per cent, reaching an all-time high of 20 per cent in the periods of lower growth (1983-1988, 1992-1998 and 2010-2013) and a record low of 7.9 per cent in the second quarter of 2007 , characterized by strong economic growth.

Second, the average frictional/mismatch unemployment rate is around 3.4 per cent, while rationing unemployment stands at around 13.6 per cent over the entire sample. These results are consistent with numerous studies that show the higher degree of institutional rigidity (employment protection regulation, unions and collective bargaining) and high levels of wage rigidity in European countries. ${ }^{26}$

Third, it is worth stressing that the estimated level of rationing unemployment registers a markedly procyclical pattern over the entire period under study, while the frictional unemployment is countercyclical, as in the US case. Finally, it should also be noted that, in our empirical decomposition, when the unemployment rate is below 10 per cent almost all unemployment is frictional.

We also analyze the robustness of the decomposition of the unemployment rate to changes in the parameters $c, \mu$, and $\eta$. The changes in the rate of frictional/mismatch unemployment are in line whith those analyzed in the US case.

\section{Conclusions}

This paper uses a new accounting technique to differentiate between frictional and rationing unemployment with a derived rigid wage-setting rule over the business cycle. Our paper follows Michaillat's (2012) approach, developing some aspects not addressed in his model. Michaillat's work assumes that eliminating frictions means making the cost of opening a vacancy equal to zero but not changing the matching friction, which implies that frictions in the labor market do not disappear. We take a different approach from Michaillat (2012), using a matching function that eliminates frictions and maintaining a positive cost for opening a vacancy. In terms of empirical methodology, our unemployment rate decomposition technique basically requires the estimation of matching parameters and observed labor market data while Michaillat calibrates the parameters and estimates productivity and wages. However, it is important to point out that the results yielded using our method are in line with the Michaillat's principal result: the frictional unemployment is countercyclical and the unemployment due

\footnotetext{
${ }^{26}$ See Blanchard et al. (1995), or more recently Jimeno and Thomas (2013). 
to rationing is procyclical. To be able to compare our technique with Michaillat's work, we use data from the US labor market, and we have additionally chosen data from the Spanish labor market to corroborate the robustness of our method and to see the differences between a flexible (US) and a rigid (Spain) labor market

With our method, we observe for the US labor market that the average unemployment rate for the recession years is 7 per cent. Over this period, the frictional unemployment is about 1.9 per cent and the rationing unemployment rate is 5.1 per cent. Moreover, as long as unemployment is below 5 per cent almost all unemployment is frictional. These numbers are roughly consistent with Michaillat's (2012) results. We also observe that over the entire period frictional unemployment accounts for 36 per cent of total unemployment.

For Spain, the decomposition of unemployment rate also follows Michaillat's patterns and we find that approximately 20 per cent of all unemployment is due to frictions in the labor market with the other 80 per cent due to job rationing problems. These results are consistent with a large body of literature for the Spanish labor market that shows the higher degree of institutional and wage rigidity. The analysis suggests that labor market policies targeted at reducing frictional unemployment will have more success in the US than in Spain for reducing unemployment.

\section{REFERENCES}

Abraham, K. G. and Katz, L. F. (1986). 'Cyclical Unemployment: Sectorial Shifts or Aggregate Disturbances?', Journal of Political Economy, Vol. 94, No. 3, pp. $507-522$.

Aguirregabiria, V. and Alonso-Borrego C. (2009). 'Labor Contracts and Flexibility: Evidence from a Labor Market reforms in Spain', Working Paper 09-18. Economic Series, Universidad Carlos III de Madrid.

Alonso-Borrego, C., Fernández Villaverde, J. and Galdó n-Sanchez, J. E. (2006). 'Evaluating Labor Market Reforms: A General Equilibrium Appoach'. IZA Discussion Papers 1129, Institute for Study of Labor (IZA).

Álvarez de Toledo, P., Núñez, F. and Usabiaga, C. (2008). 'La Función de Emparejamiento en el Mercado de Trabajo Español', Revista de Economía Aplicada, Vol. 16, No. 3, pp. 5-35.

Barnichon, R. and Figura A. (2011). 'What Drives Matching Efficiency? A Tale of Composition and Dispersion'. Finance and Economics Discussion Series 201110, Board of Governors of the Federal Reserve System.

Barnichon, R. and Figura A. (2013). 'Labor Market Heterogeneity and the Aggregate Matching Function', American Economic Journal:Macroeconomics, American Economic Association, Vol. 7(4), pp. 222-49, October.

Blanchard, O. J. and Galí, J. (2010). 'Labor Markets and Monetary Policy: A New-Keynesian Model with Unemployment', American Economic Journal: Macroeconomics, Vol. 2, No. 2, pp. 1-30. 
Blanchard, O., Jimeno, J., Andrés, J., Bean, C., Malinvaud, E., Revenga, A., SaintPaul, G., Snower, D., Solow, R., Taguas, D. and Toharia, L. (1995). Spanish Unemployment: Is there a Solution?, CEPR.

Brown A. J., Merkl, C. and Snower, D. J. (2015). 'An Incentive Theory of Matching', Macroeconomic Dynamics, Vol. 19, No. 3, pp. 643-668.

Burda, M. and Wyplosz, C. (1994). 'Gross Worker and Job Flows in Europe', European Economic Review, Vol. 38, No. 6, pp. 1287-1315.

Cahuc, P., Carcillo, S. and Zylberberg, A. (2014). Labor Economics, 2nd edn, The MIT Press.

Fair, R. C. and Taylor, J. B. (1983). 'Solution and Maximum Likelihood Estimation of Dynamic Nonlinear Rational expectations Models', Econometrica, Vol. 51, No. 4, pp. 1169-1185.

Hagedorn, M. and Manovskii, I. (2008). 'The Cyclical Behavior of Equilibrium Unemployment and Vacancies Revisited', American Economic Review, Vol. 98, No. 4, pp. 1692-1706.0-65.

Herz, B. and Rens, T. (2011). 'Structural Unemployment', Working paper 1276, Universitat Pompeu Fabra. Departament d'Economia i Empresa.

Jimeno, J. F. and Thomas, C. (2013). 'Collective Bargaining, Firm Heterogeneity and Unemployment', European Economic Review, Vol. 59, pp. 63-79

Kocherlakota, N. (2010). Inside the FOMC. Speech in Marquette, MI, President of the Federal Bank of Minneapolis, August 17.

Krugman, P. (2010). 'Structure of Excuses'. New York Times, September 27.

Michaillat, P. (2012). 'Do Matching Frictions Explain Unemployment? Not in Bad Times', American Economic Review, Vol. 102, No. 4, pp. 1721-1750.

Mortensen, D. and Pissarides, C. (2001). 'Taxes, Subsidies and Equilibrium Labour Market Outcomes', CEPR Discussion Papers 2989, C.E.P.R. Discussion Papers.

Peracchi, F. and Viviano, E. (2004). 'An Empirical Micro Matching Model with an Application to Italy and Spain', Economic Working Paper 538, Economic Research Department (Bank of Italy).

Petrongolo, B. and Pissarides, C. A. (2001). 'Looking into the Black Box: A Survey of the Maching Function', Journal of Economic Literature, Vol. 39, pp. $390-431$.

Pissarides, C. A. (2000). Equilibrium Unemployment Theory, 2nd edn, The MIT Press.

Pissarides, C. A. (2009). 'The Unemployment Volatility Puzzle: Is Wage Stickiness the Answer?', Econometrica, Vol. 77, No. 5, pp. 1339-1369.

Shimer, R. (2005). 'The Cyclical Behavior of Equilibrium Unemployment and Vacancies', The American Economic Review, Vol. 95, No. 1, pp. 25-49.

Sala, H. and Silva, J. I. (2009). 'Flexibility at the Margin and Labour Market Volatility: The Case of Spain', Investigaciones Económicas, Vol. XXXIII, No. 2, pp. $145-178$.

Silva, J. I. and Toledo, M. (2009). 'Labor Turnover Costs and the Cyclical Behavior of Vacancies and Unemployment', Macroeconomic Dynamics, 13, Supplement S1, pp. 76-96.

Stevens, M. (2007). 'New Microfoundations for the Aggregate Matching Function', International Economic Review, Vol. 48, No. 3, pp. 847-868.

Yashiv, E. (2006). 'Evaluating the Performance of the Search and Matching Model', European Economic Review, 50, pp. 909-936. 